\title{
Impact of Buyers' Emotions on Perceived Behavioral Control
}

\author{
Jing Tian ${ }^{1}$ \\ ${ }^{1}$ School of Economics and Management, Tsinghua University, Beijing 100084, China \\ Correspondence: Jing Tian, School of Economics and Management, Tsinghua University, Beijing 100084, China
}

Received: November 2, 2017

Accepted: February 13, 2018

Online Published: February 14, 2018

doi:10.5430/bmr.v7n1p42

URL: https://doi.org/10.5430/bmr.v7n1p42

\begin{abstract}
This study focuses on how emotions of different types affect perceived behavioral control (PBC), which, by referencing to service marketing and organizational behavior theory, is divided into three aspects: perceived participation (PP), perceived risk (PR), and perceived organizational support (POS) here. To explore how different types of emotions affect these three variables respectively, subjects' emotions are controlled through experiment. Results reveal that the type of emotion has significant influence on the three variable values. Positive emotion parallels the highest PP and POS values, while neutral emotion comes with the lowest PR value.
\end{abstract}

Keywords: emotion, perceived participation, perceived risk, perceived organizational support

\section{Research Question}

China is becoming the world's most promising market thanks to an enormous population and expanding purchasing power. To tap the full potential of this huge market requires intensive study of Chinese consumers. Stimulating consumption and fueling domestic demand are now key drivers of China's GDP growth.

PBC refers to people's perceptions of their ability to perform a given behavior. Drawing an analogy to the expectancy- value model of attitude PBC, as most scholars believe, can accurately predict the purchase intention of buyers (Ajzen, 1991; Hui \& Bateson, 1991; Notani Notani, 1998; Kidwell and Jewell, 2003). There is plenty of research on emotions and consumers' purchase decisions, while few researcher turn their eyes tot how do emotions impact the decision making process. This thesis presents three PBC variables: PP, PR, and POS by referencing the study of emotion and consumer behaviors in service marketing theory and social psychology, and explores different values of the variables changing to emotions of varying types.

\section{Literature Review}

\subsection{Emotions}

Research and literature related to emotions are already in massive number. How the complex-by-nature emotions are defined and understood, however, varies among scholars from different fields and different perspectives. James (1890) defined emotion as "adaptive behavior and physiological tendency" from the perspective of response tendency; Leeper (1948) "takes emotions to act essentially as motives, pervading and organizing behavior"; Lazarus (1984) defines, from interaction with environment, emotion as "an physiological and psychological responses to good or bad information in the present situation"; Campos focused on the relation between emotions and stimulus, and characterized emotions as "processes of establishing, maintaining, and disrupting the relations between the person and the internal or external environment, when such relations are significant to the individual". Emotions, as widely recognized by Chinese scholars, refer to people's attitudes, experience, and behavior actions to objective entities, thus a complicate mix of emotional experience, emotional behaviors, emotional arousal, and perception of emotional stimulation.

Emotion evoking is a must to explore emotions, intentions and behaviors. Li Xiaobin (2011) summarized five methods of emotion evoking in his master's thesis. First, contagion by watching films, pictures, or photos; second, memory, to be specific, reproducing things perceived, thought, and operated before; third, expression, which not only can intensify the original emotion, but also can directly evoke new emotion; and the last two are scenario and task, which would trigger specific emotion, respectively.

Next, evoked emotions must be measured, a basis of further analysis and research. Emotions first are divided into explicit and implicit ones. Explicit emotions are then measured by the following methods: self-report, in which subjects need to report their internal feelings after emotional stimulation; physiological measurement that covers 
nervous system, electroencephalogram, and neuroimaging; and behavior measurement, including shock response, acoustic properties, facial expression, and body posture. As research on implicit emotion measurement are few in number, longitudinal design and multi-method design are adopted.

\subsection{Emotion and Consumers' Decision Making}

Emotion has been a recent focus for decision making research, and the two topics have been popular among all research communities. Featuring multiple components, microstructures and dimensions, emotion is a process of psychological activities and motive that interacts with recognition for the living being to survive and communicate with others (Meng Zhaolan, 1994). .From a psychological perspective, the emphasis is on the implicit mechanism through which emotions affect decision making and the relation between emotion and perception. What role do emotions play in the decision making process? How it works? What is the internal mechanism? These issues are what psychologists focus on. The following theoretical models explain the implicit mechanism. Risk as feelings, proposed by Loewenstein et al. (2001), holds that the decision making process involves both anticipated emotions subject to cognitive appraisal and immediate emotions immune from cognitive evaluation. These emotions can have direct impact on decision making and cognitive evaluation. Feelings information, first introduced by $\mathrm{Cl}$ ore and Schwarz (1994), indicates that emotions as thread have immediate impact on people's judgements. In the process of evaluating and judging, individuals always ask themselves for how they feel themselves, and depend their own feelings information for decision making. Emotions play a significant role in consumers' cognitive process (Li Binxiao, 2011), and the fact that emotional response can impact decision making and behaviors has already been evidenced by countless research (Roehm, 2005; Shiv and Fedorikhin, 1999).

\subsection{PBC}

The Theory of Planned Behavior (TPB) has huge influence in studying behavioral intention, and it presents three variables of attitude, subjective norm, and perceived behavioral control to decide on behavioral intention. PBC reflects the extent of perceived difficulty to start a behaviour, to be specific, individual's personal ability and behavioral characteristics, e.g. whether cooperation with others is required. Ajzen et al. (2005) stated that PBC includes two components: first, controllability to measure if one can successfully execute a given behaviour, and second, self-efficacy, determined by perceived ease-difficulty or confidence that one is capable of performing the target behaviour.

TPB and plenty of empirical research shows that PBC can well explain customers' behavioral intentions and customer behaviors. As enterprises pay increasing attention to marketing, customers' own abilities are no longer the only determiner on their purchasing intentions and behaviors (e.g. money and time), for enterprises' marketing stimuli come into play. During the financial crisis of 2008, all major car brands saw sharp decline in America, except for Hyundai, which maintained continuous growth. Such huge difference must be attributed to Hyundai's commitment to customers that all Hyundai branded cars could be sold back to Hyundai at set prices if customers lost their jobs. This campaign minimizes the risk customers perceive, who can then make a determined buying decision despite of the economic downturn. In recent years, banks start to offer loan with zero down payment. Though not any increase in customers' salary or purchasing power, customers are encouraged to purchase, an obvious evidence of the close relation between organizational support and purchasing intention. Similar examples can be found everywhere, like Nike Innovation Works and Apple App Store that leverages customers' creative resources and get customers involved in their product development and marketing.

Existing research on marketing sheds little light on PBC factors subject to external impacts like enterprise marketing events. As these concepts have been studied in social psychology and organizational behaviour, PBC here is further divided into three dimensions: perceived risk, perceived organizational support and customer participation based on marketing.

\subsection{Research on Emotion Classification}

Wundt (1896) was the first to study emotional dimensions, and proposed the three-dimensional theory of emotion (pleasure and displeasure, excitement and inhibition [tranquillization], tension and relaxation). From then on, a great deal of scholars followed to define and divide emotion dimensions. Plutchik (1970) assumed that emotions differ in three ways: intensity, similarity to one another, and polarity or oppositeness; Izard (1977) divided emotions into four dimensions: pleasantness, tension, impulsiveness and self-assurance; Watson and Tellegen (1985) found a two-dimensional structure: positive affect (PA) and negative affect (NA).

$\mathrm{Li}$, Li and Ling (2009) unveiled the influence of positive emotions on buying decisions from three aspects -- risk decision, diverse exploratory behaviour and experiential decision-making. With regard to consumers' 
decision-making behavior, Barone and Romeo (2000) believed that positive emotions could encourage consumers to show diverse exploratory behaviour like extensive information searching, while Chuang Kung and Sun (2008) concluded that participants under negative affects show more exploratory behaviour. Individuals in positive emotions are more prudent in making investment decisions (Nygren, 1996), while those suffering negative emotions are prone to take risks (Isen and Partrick, 1983).

Consumers of specific emotions tend to turn their eyes and ears to information matching with their emotions. Positive emotions push consumers to take a panoramic view of the situation, but consumers of negative emotions pay more attention to details. According to mood-congruent effect, positive emotion facilitates processing and extracting of positive information, and vice versa. Positive emotion individuals perform better in analogic reasoning tasks, compared to negative-emotion ones excellent in insightful analysing tasks.

\section{Research Model and Experimental Design}

\section{(I) Research Model}

Research purpose, as supported by the literature review, is clear: to explore how emotions of different types influence PBC, in other words, whether there is any difference in the consumers' PR, PCP and POS when undergoing positive, neutral and negative emotions. The following research framework, therefor, is put forward, as shown in Figure 1.

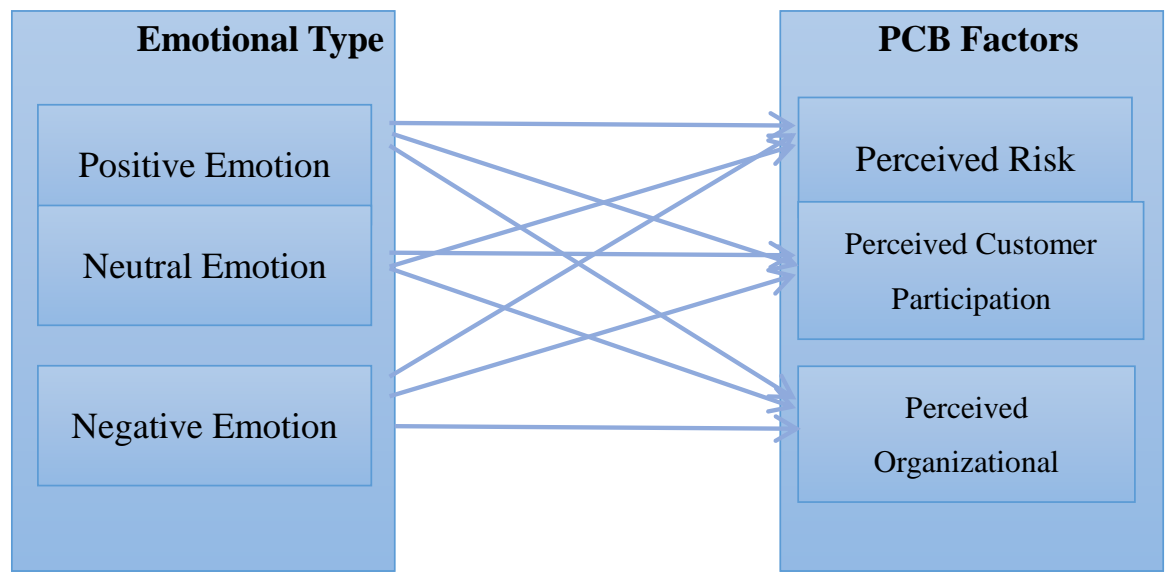

Figure 1.

\section{(II) Definitions}

1. Emotions: people's attitude, experience, and corresponding behaviour or actions to objective entities, a complex mix of emotional experience, emotional behaviour, emotional arousal, and perception of emotional stimulation.

2. Perceived risk: the consumer's feeling of uncertainty about the consequences of transactions (Bauer, 1960). It involves two components: 1) uncertainty, i.e. subjective probability for the results of decisions taken; and 2) its consequence, i.e. the importance of the consequences of a failed choice (Shumway, 2001).

3. Perceived customer participation: the provision of relevant mental and material resources to the product with varying levels of effort and involvement (Cermak, File and Prince, 1994).

4. Perceived organizational support: customers care about that whether organizations value their input and are concerned about their presence (Bettencourt, 1997).

5. Perceived behavior control: the extent of perceived ease-difficulty to start a behavior. (Ajzen et al. 1991; 2005)

\section{(III) Research Methods}

Changes in PR, PCP and POS values are measured through experiments by controlling the type of emotion in each situation. Researchers can control the research environment to adjust variable values independently. By observing the dependent variable's changing curve, researcher can infer the relationship between independent variables and dependent ones. Considering the difficulty to measure emotions, experimentation offers an effective way to limit emotion changes and eliminate other influencing factor. That's how observed changes in dependent variables can be recognized changes in experimental variables.

Emotions are critical to consumers' cognitive process (Li Xiaobin, 2011), and a lot of research proves that emotional response can impact decision making and behaviors (Roehm, 2005; Shiv and Fedorikhin, 1999). Based on existing 
papers on emotions, emotions are classified into three types: positive, negative and neutral. A $3 * 3$ research model is designed to compare changes in PR, PCP and POS by setting different emotions.

\section{Experiment and Data Analysis}

\section{(I) Experimental Process}

\section{Sample selection}

Three groups of emotions (positive, negative, neutral) and three groups of PBC factors (perceived risk, customer participation and perceived organizational support) are chosen for between-group design. Students are sampled for two reasons: they have little difference in terms of general knowledge and social experience, which will reduce interference and increase internal experimental effectiveness; and they (including college students and postgraduates) are soon-to-be major consumers, and analysing them is highly informative for future decision making by enterprises. Undergraduates from seven colleges in central China were chosen randomly, all providing their email, QQ (MSN) and phone number. To further boost their interest and enthusiasm for the experiment, all participants were informed that a small gift (valuing 5 yuan) would be granted when they submitted the questionnaire. A total of 327 questionnaires were collected, and 298 are effective (91.3\%), including 164 PR samples in five groups (two each for positive emotion and negative emotions, and one for neutral emotions), $60 \mathrm{CP}$ samples in three groups (positive, negative and neutral emotions), and 74 effective POS samples in three groups (positive, negative and neutral emotions).

Table 1. Characteristics of Sample Distribution

\begin{tabular}{|c|c|c|c|}
\hline \multicolumn{2}{|c|}{ Sample Characteristics } & Frequency & Rate of Frequency \\
\hline \multirow[t]{2}{*}{ Gender } & Male & 86 & 52.4 \\
\hline & Female & 78 & 47.6 \\
\hline \multirow{3}{*}{ Age } & $<25$ & 149 & 90.9 \\
\hline & $25-35$ & 14 & 8.5 \\
\hline & $>35$ & 1 & 0.6 \\
\hline \multirow{4}{*}{$\begin{array}{l}\text { Monthly } \\
\text { Disposal } \\
\text { Income }\end{array}$} & $<1000$ yuan & 109 & 66.4 \\
\hline & 1,000 - 1,500 yuan & 40 & 24.4 \\
\hline & $1,500-2,000$ yuan & 13 & 7.9 \\
\hline & $>2,000$ yuan & 2 & 1.2 \\
\hline
\end{tabular}

2. Measurement of variables

Playing distinctive PPTs arises corresponding types of emotions in participants. To trigger positive ones, bright-colored pictures depicting an optimistic attitude to life are projected in a row, along with cheerful music. By contrast, gloomy pictures of pessimism paired with sad music are played to make participants feel negative. For neutral emotions, pictures of everyday things are presented against regular rhythm. To guarantee effective emotional control, we have called back these participants randomly half a month later by phone or email, and they were required to recall the type of emotion they perceived in the PPT presentations, all offering correct answers. It shows that the emotional control is accurate and effective. The seven-point Likert scale was adopted to evaluate all items, with " 1 for strong disagree, 2 for disagree, 3 for somewhat disagree, 4 for neither agree or disagree, 5 for somewhat agree, 6 for agree, and 7 for strong agree". Existing scales and a self-designed questionnaire are used for measuring independent variables. As can be seen in Table 2 below, the results of reliability analysis are good for all variable measurement. 
Table 2. Reliability Analysis

\begin{tabular}{|c|c|c|c|}
\hline Variable & $\begin{array}{l}\text { Numbe } \\
\mathrm{r}\end{array}$ & Content & Cronbach $\alpha$ \\
\hline \multirow[t]{3}{*}{$\begin{array}{l}\text { Perceived } \\
\text { Risk }\end{array}$} & A1 & $\begin{array}{l}\text { I think that my relatives and friends will have bad thoughts } \\
\text { about me if what I buy is not accepted by them. }\end{array}$ & \multirow[t]{3}{*}{0.751} \\
\hline & A5 & $\begin{array}{l}\text { I think a bad (crowded, noisy ...) shopping environment is likely } \\
\text { to cause negative emotions }\end{array}$ & \\
\hline & A7 & I'm afraid that the products may not work & \\
\hline \multirow{6}{*}{$\begin{array}{l}\text { Customer } \\
\text { Participati } \\
\text { on }\end{array}$} & $\mathrm{C} 2$ & I will report my requirements on products to their salesperson & \multirow[t]{6}{*}{0.732} \\
\hline & $\mathrm{C} 4$ & $\begin{array}{l}\text { I will report my suggestions for service improvement to } \\
\text { salesperson }\end{array}$ & \\
\hline & C6 & $\begin{array}{l}\text { I will report my suggestions for service improvement to } \\
\text { salesperson }\end{array}$ & \\
\hline & $\mathrm{C} 8$ & I have good relationships with certain salesperson & \\
\hline & $\mathrm{C} 10$ & I will contact certain salespersons when encountering problems. & \\
\hline & $\mathrm{C} 13$ & $\begin{array}{l}\text { I will contact salesperson even if such problems bring no } \\
\text { troubles to myself. }\end{array}$ & \\
\hline \multirow{3}{*}{$\begin{array}{l}\text { Perceived } \\
\text { Organizati } \\
\text { onal } \\
\text { Support }\end{array}$} & B2 & $\begin{array}{l}\text { Favorable state polices for the product (e. g. subsidy program } \\
\text { for rural appliance purchases, old for new service, a cut in } \\
\text { purchase tax) }\end{array}$ & \multirow[t]{3}{*}{0.748} \\
\hline & B4 & Merchants (manufacturers) hold VIP sales & \\
\hline & B5 & $\begin{array}{l}\text { Merchants (manufactures) have good attitude when dealing with } \\
\text { after-sales maintenance and customer complaints }\end{array}$ & \\
\hline
\end{tabular}

\section{Data analysis}

The experimental data were analysed to identify how does emotional type influence PBC. First, a descriptive analysis is given to three variables (mean) under each emotional type. Results are provided in Table 3 and Figure 2.

Table 3. Impact of Emotions on PBC (Mean)

\begin{tabular}{l|l|l|l}
\hline & Positive & Neutral & Negative \\
\hline $\begin{array}{l}\text { Perceived } \\
\text { Risk }\end{array}$ & 3.5232 & 3.8602 & 3.2560 \\
\hline $\begin{array}{l}\text { Perceived } \\
\text { Customer } \\
\text { Participation }\end{array}$ & 4.1970 & 3.7733 & 3.3889 \\
\hline $\begin{array}{l}\text { Perceived } \\
\text { Organizational } \\
\text { Support }\end{array}$ & 3.9583 & 3.9028 & 2.9643 \\
\hline
\end{tabular}

\section{Figure 2a Perceived Risk}

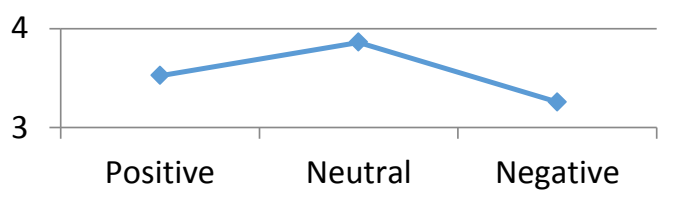


Figure 2b Perceived Customer...

\section{4}

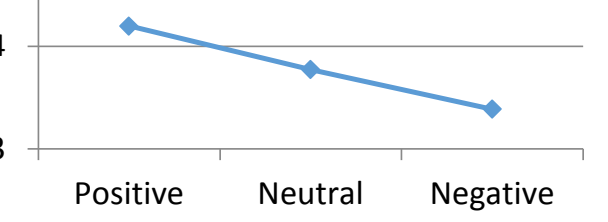

\section{Figure 2c Perceived Organizational...}

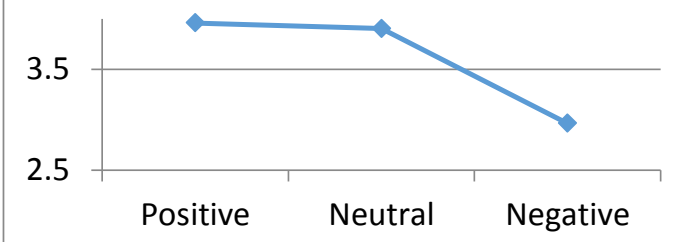

According to Table 3, participants of all three types of emotion have positive responses to PR, PCP and POS (Mean $\geq 3$ ), meaning that emotion can be controlled in all scenarios. Based on Figure $2 \mathrm{a} / \mathrm{b} / \mathrm{c}$, the three variables are lowest in the negative-emotion scenario, while neutral emotions brings the highest PR, and positive emotions the highest PCP and POS.

Next one-way ANOVA was adopted to find how emotional type influence PBC variables. See Table 4 and Table 5 below.

Table 4. One-way ANOVA of Different Emotions

\begin{tabular}{|c|c|c|c|c|c|c|c|}
\hline & & SS & $\mathrm{DF}$ & MS & $\mathrm{F}$ & Sig. & $\begin{array}{l}\text { Test for } \\
\text { Equality } \\
\text { of } \\
\text { Variances }\end{array}$ \\
\hline \multirow[t]{3}{*}{ Perceived Risk } & $\begin{array}{l}\text { SS } \\
\text { Between }\end{array}$ & 7.398 & 2 & 3.699 & 3.103 & .048 & .639 \\
\hline & SS Within & 194.322 & 163 & 1.192 & & & \\
\hline & SS Total & 201.720 & 165 & & & & \\
\hline \multirow{3}{*}{$\begin{array}{l}\text { Perceived } \\
\text { Customer } \\
\text { Participation }\end{array}$} & $\begin{array}{l}\text { SS } \\
\text { Between }\end{array}$ & 5.962 & 2 & 2.981 & 3.392 & .040 & .408 \\
\hline & SS Within & 51.844 & 59 & .879 & & & \\
\hline & SS Total & 57.805 & 61 & & & & \\
\hline \multirow{3}{*}{$\begin{array}{l}\text { Perceived } \\
\text { Organizational } \\
\text { Support }\end{array}$} & $\begin{array}{l}\text { SS } \\
\text { Between }\end{array}$ & 16.548 & 2 & 8.274 & 4.844 & .011 & .016 \\
\hline & SS Within & 124.696 & 73 & 1.708 & & & \\
\hline & SS Total & 141.244 & 75 & & & & \\
\hline
\end{tabular}

Table 4 reveals a significant difference in the performance of all the three PBC variables in different scenarios.

Pairwise tests further compare the three types in pair accordingly. LSD test was selected for PR and PCP, and

Tamhane test for POS because its homogeneity test of variances failed. 
Table 5. Pairwise Analysis of Different Emotions

\begin{tabular}{|c|c|c|c|c|c|}
\hline & Emotion I & Emotion $\mathrm{J}$ & Mean Variance (I-J) & SE & Significance \\
\hline \multirow{6}{*}{$\begin{array}{l}\text { Perceived Risk } \\
\text { (LSD) }\end{array}$} & \multirow[t]{2}{*}{ Positive } & Neutral & -.33701 & .23140 & .147 \\
\hline & & Negative & .26725 & .19073 & .163 \\
\hline & \multirow[t]{2}{*}{ Neutral } & Positive & .33701 & .23140 & .147 \\
\hline & & Negative & $.60426^{*}$ & .24443 & .014 \\
\hline & \multirow[t]{2}{*}{ Negative } & Positive & -.26725 & .19073 & .163 \\
\hline & & Neutral & $-.60426^{*}$ & .24443 & .014 \\
\hline \multirow{6}{*}{$\begin{array}{l}\text { Perceived } \\
\text { Customer } \\
\text { Participation } \\
\text { (LSD) }\end{array}$} & \multirow[t]{2}{*}{ Positive } & Neutral & .42364 & .27402 & .127 \\
\hline & & Negative & $.80808^{*}$ & .31388 & .013 \\
\hline & \multirow[t]{2}{*}{ Neutral } & Positive & -.42364 & .27402 & .127 \\
\hline & & Negative & .38444 & .30615 & .214 \\
\hline & \multirow[t]{2}{*}{ Negative } & Positive & $-.80808^{*}$ & .31388 & .013 \\
\hline & & Neutral & -.38444 & .30615 & .214 \\
\hline \multirow{6}{*}{$\begin{array}{l}\text { Perceived } \\
\text { Organizational } \\
\text { Support } \\
\text { (Tamhane) }\end{array}$} & \multirow[t]{2}{*}{ Positive } & Neutral & .05556 & .31964 & .997 \\
\hline & & Negative & $.99405^{*}$ & .36927 & .029 \\
\hline & \multirow[t]{2}{*}{ Neutral } & Positive & -.05556 & .31964 & .997 \\
\hline & & Negative & .93849 & .38274 & .053 \\
\hline & \multirow[t]{2}{*}{ Negative } & Positive & $-.99405^{*}$ & .36927 & .029 \\
\hline & & Neutral & -.93849 & .38274 & .053 \\
\hline
\end{tabular}

As Table 5 shows, for PR, a significant difference exists between neutral and negative emotion, with an overall a reverse V curve. As for PCP and POS, a significant difference exists between positive and negative emotion, and the measured value decreases with the change from position to negative emotion.

\section{Conclusion and Inspiration}

\subsection{Conclusion}

The research reveals that different types of emotions can influence PR, PCP and POS to different degrees, indicating that controlling emotion control is an effective way to decide consumers' buying decisions.

Test data shows a much higher PR corresponding to neutral emotions than that of negative emotions. Psychologically, consumers are more sensitive to loss than gains of the same amount. In other words, consumers of negative emotion may be insensitive to loss already, thus perception of less risks. This is consistent with existing research conclusions -- individuals in negative condition are more likely to take risk (Isen \& Partrick, 1983).

PCP value is significantly higher when participants are positive rather than negative. This coincides with Barone Miniard \& Romeo (2000), who pointed out that positive emotions would encourage consumers to show diverse exploratory behaviors like extensive information search. Such exploratory behavior of information search represents a key form of customer participation. As PCP includes also the intention of customers to communicate and interact with salespersons, it is also proved that positive emotions, compared to negative ones, can better promote communication and negotiation between customers and staff. thus guarantee smooth buying decisions by customers. This has also been proved in previous researches: positive emotions can promote effective negotiation, while negative emotions are another way around (Carnevale and Isen, 1986; Kopelman Rosette and Thompson, 2006).

Similarly, customers perceive much more organizational support when they have positive emotions than negative ones. According to mood congruence theory, individuals usually incline to pay attention to events congruent with their current emotions. In other words, positive customers are more likely to notice the discount and other supportive behaviour, while negative customers may believe their efforts and input are not recognized, and become insensitive to organizational support. Negative emotions, therefore, may damper customers' perception of organizational support. 


\subsection{Inspiration}

Results show significant differences in PR, PP and POS values for consumers experiencing different types of emotions. The thesis offers a theoretical explanation of the inner mechanism for how emotions impact consumer's purchasing decisions.

Positive emotions contribute to higher PP and POS values than that of other types of emotions. For that reason, enterprises can keep customers in positive emotions through music, scene setting, and atmosphere building for enhance POS, thus better PBC and smooth purchasing decision.

The highest PR value is seen with neutral emotions. Obviously, enterprises should try to prevent consumers from staying in neutral emotions, and lead them to feel positive. Neutral emotions will easily trigger rational thinking in consumers. Consideration of potential risk in the purchase will be an obstacle for consumers to make smooth purchasing decisions.

\section{References}

Ajzen, Icek, \& Martin Fishbein. (2005). The influence of attitudes on behavior. The handbook of attitudes, 173(221), 31.

Ajzen, Icek. (991). The theory of planned behavior. Organizational behavior and human decision processes, 50(2), 179-211. https://doi.org/10.1016/0749-5978(91)90020-T

Barone, Michael J., Paul W. Miniard, \& Jean B. Romeo. (2000). The influence of positive mood on brand extension evaluations. Journal of consumer Research, 26(4), 386-400. https://doi.org/10.1086/209570

Bauer, Raymond A. (1960). Consumer behavior as risk taking. Proceedings of the 43rd National Conference of the American Marketing Assocation, June 15, 16, 17, Chicago, Illinois, 1960. American Marketing Association.

Bettencourt, Lance A. (1997). Customer voluntary performance: Customers as partners in service delivery. Journal of retailing, 73(3), 383-406. https://doi.org/10.1016/S0022-4359(97)90024-5

Campos, Joseph J., Rosemary G. Campos, \& Karen C. Barrett. (1989). Emergent themes in the study of emotional development and emotion regulation. Developmental Psychology, 25(3), 394.

Carnevale, Peter JD, \& Alice M. Isen. (1986). The influence of positive affect and visual access on the discovery of integrative solutions in bilateral negotiation. Organizational behavior and human decision processes, 37(1), 1-13. https://doi.org/10.1016/0749-5978(86)90041-5

Cermak, Dianne SP, Karen Maru File, \& Russ Alan Prince. (1994). Customer participation in service specification and delivery. Journal of applied business research, 10(2), 90.

Chuang, Shih-Chieh, Chaang-yung Kung, \& Ya-Chung Sun. (2008). The effects of emotions on variety-seeking behavior. Social Behavior and Personality: an international journal, 36(3), 425-432. https://doi.org/10.2224/sbp.2008.36.3.425

Clore, Gerald L., Norbert Schwarz, \& Michael Conway. (1994). Affective causes and consequences of social information processing. Handbook of social cognition, 1, 323-417.

Hui, Michael K., \& John EG Bateson. (1991). Perceived control and the effects of crowding and consumer choice on the service experience. Journal of consumer research, 18(2), 174-184. https://doi.org/10.1086/209250

Isen, Alice M., \& Robert Patrick. (1983). The effect of positive feelings on risk taking: When the chips are down. Organizational behavior and human performance, 31(2), 194-202. https://doi.org/10.1016/0030-5073(83)90120-4

Izard, Carroll E. (1992). Basic emotions, relations among emotions, and emotion-cognition relations. 561.

James, William. (1890). The consciousness of self. The principles of psychology 8.

Kidwell, Blair, \& Robert D. Jewell. (2003). An examination of perceived behavioral control: internal and external influences on intention. Psychology \& Marketing, 20(7), 625-642. https://doi.org/10.1002/mar.10089

Kopelman, Shirli, Ashleigh Shelby Rosette, \& Leigh Thompson. (2006). The three faces of Eve: Strategic displays of positive, negative, and neutral emotions in negotiations. Organizational Behavior and Human Decision Processes, 99(1), 81-101. https://doi.org/10.1016/j.obhdp.2005.08.003

Lazarus, Richard S. (1984). On the primacy of cognition. 124.

Leeper, Robert W. (1948). A motivational theory of emotion to replace 'emotion as disorganized response.' 
Psychological review, 55(1), 5.

Li Aimei, Li Lianqi \& Ling Wenquan. (2009). Review of effects of positive emotion on consumer decision behaviour. Consuming economics, 3, 39-42.

Li Binxiao. (2011). Impact of Emotional Intensity to Time Distance [D]. Qufu Normal University.

Loewenstein, G. F., Weber, E. U., Hsee, C. K., \& Welch, N. (2001). Risk as feelings. Psychological bulletin, 127(2), 267.

Notani, Arti Sahni. (1998). Moderators of perceived behavioral control's predictiveness in the theory of planned behavior: A meta-analysis. Journal of consumer psychology, 7(3), 247-271. https://doi.org/10.1207/s15327663jcp0703_02

Nygren, Thomas E., et al. (1996). The influence of positive affect on the decision rule in risk situations: Focus on outcome (and especially avoidance of loss) rather than probability. Organizational behavior and human decision processes, 66(1), 59-72. https://doi.org/10.1006/obhd.1996.0038

Plutchik, Robert. (1970). Emotions, evolution, and adaptive processes. Feelings and emotions: the Loyola Symposium. Academic Press, New York. https://doi.org/10.1016/B978-0-12-063550-4.50007-3

Roehm Jr, Harper A., \& Michelle L. Roehm. (2005). Revisiting the effect of positive mood on variety seeking. Journal of Consumer Research, 32(2), 330-336. https://doi.org/10.1086/432242

Shiv, Baba, \& Alexander Fedorikhin. (1999). Heart and mind in conflict: The interplay of affect and cognition in consumer decision making. Journal of consumer Research, 26(3), 278-292. https://doi.org/10.1086/209563

Shumway, Tyler. (2001). Forecasting bankruptcy more accurately: A simple hazard model. The Journal of Business, 74(1), 101-124. https://doi.org/10.1086/209665

Watson, David, \& Auke Tellegen. (1985). Toward a consensual structure of mood. Psychological bulletin, 98(2), 21(1985)9.

Wundt, Wilhelm Max. (1896). Grundriss der psychologie. W. Engelmann. 